\title{
Computation of Soil Moisture using Passive Microwave Remote Sensing - An ANN Approach
}

\author{
Veena C.S. \\ Barkatullah University Institute of Technology \\ Bhopal, Madhya Pradesh, India
}

\author{
Poonam Sinha \\ Barkatullah University Institute of Technology \\ Bhopal, Madhya Pradesh, India
}

\begin{abstract}
An empirical model incorporating the effects of vegetation and surface roughness has been proposed which uses the least square fit of a third order polynomial using real time data. Further an Artificial Neural Network (ANN) architecture has been developed using back propagation algorithm to train the neural network which predicts coefficients of the model for a given radiometer data. The accuracy of the proposed model and the performance of the ANN architecture have been ascertained by comparing the results with the in-situ measured values of soil moisture.
\end{abstract}

\section{Key words}

Emissivity, passive microwave remote sensing, NDVI, Dielectric permittivity, Soil moisture.

\section{INTRODUCTION}

Remote sensing of soil moisture from satellites is a promising alternative to ground measurement. Microwave frequencies are most often used both in active and passive remote sensing instruments to estimate soil moisture [1].The advantage of microwave remote sensing is that it provides extended soil moisture estimations, girded on averaged surface (foot prints) from tens of meters to $50 \mathrm{~km}$ resolution and the measurement can be made directly while the target or the sensor is under motion.

The theory behind microwave remote sensing of soil moisture is based on the large contrast between the dielectric properties of liquid water $(\sim 80)$ and dry soil $(<4)$.

The dielectric properties of wet soil were studied by several investigators [2],[3], [4]. As the moisture content increases, the dielectric constant of the soil water mixture increases and the change is detectable by microwave sensors [5]. The effect of moisture on the dielectric properties of soil is a very active area of research and several researchers have proposed many models. John .O. Curtis [6] has demonstrated the strong dependence of dielectric permittivity on the volumetric moisture of a sample at a given frequency. Several researchers [7- 12] have proposed such models and developed soil moisture probes based on this principle. However these models have not incorporated the necessary corrections for vegetation and surface roughness. Hence an empirical model which accounts for the above effects have been proposed in this paper and the accuracy of the model has been ascertained by comparing the computed soil moisture values using the proposed model and the measured values of the soil moisture. It is obvious that the co-efficients of the proposed model are functions of system parameters such as frequency or wavelength, look angle, polarization and surface parameters like complex dielectric constant, vegetation or crop cover (NDVI), surface roughness, local surface slope. As these parameters are different for different sites, the co- efficients of the model need to be computed every time for different sets of data. In order to overcome this problem, ANN architecture has been designed which can accurately predict the coefficients of the model for a set of input data. ANN is a powerful tool which can be very effectively applied to the problem in which the input-output relationship is not explicitly established. It is a model free estimator as it does not rely on an assumed form of the underlying data [13]. This tool is being used in several problems of soil moisture retrieval [14]-[15]. But for the first time in this paper ANN is used to predict the co-efficients of the model. This paper is organized as follows; in section 2 basic mathematical theory related to the computation of volumetric soil moisture content is briefed. Proposed empirical model is explained in section 3 . Design of ANN architecture is explained in section 4 and the relevant analysis is carried out in section 5 .

\section{MATHEMATICAL RELATIONSHIP}

Exhaustive research in the area of behavior of microwave signals upon impingent on earth surface has proved that, the emitted microwave energy is proportional to the product of surface emissivity and surface temperature which is commonly referred to as the microwave brightness temperature $(\mathrm{Tb})$. For typical soil moisture applications using longer microwave wavelengths at low altitude, temperature contributions from the atmosphere and the sky can be neglected. Thus, the brightness temperature of an emitter of microwave radiation is related to the physical temperature of the source through the emissivity such that:

$\mathrm{Tb}=(1-\mathrm{R})(\mathrm{Tsfc})=(\mathrm{e})(\mathrm{Tsfc})$

Where, $\mathrm{R}$ is the smooth surface reflectivity, Tsfc is the thermometric temperature of the soil surface and $e=(1-R)$ is the emissivity which depends on the dielectric constant of the medium being measured [16]. Although the emissivity and $\mathrm{Tb}$ are linearly related, water has a non linear dependence on reflectivity. This is because of the non linear relationship of reflection co-efficient of the water with the dielectric constant of water. The reflectivity is described by the Fresnel's equation which defines the behavior of electromagnetic waves at a smooth dielectric boundary. For horizontally polarized waves $(\mathrm{H})$ at non- nadir incidence $(\alpha)$, the Fresnel's reflection co-efficient is given by

$$
R(H \alpha)=\frac{\left|\cos \alpha-\sqrt{€-\sin ^{2} \alpha}\right|^{2}}{\left|\cos \alpha+\sqrt{€-\sin ^{2} \alpha}\right|^{2}}
$$

Where $€$ is the complex dielectric constant of the emitter. Since the angle of incidence is equal to the angle of reflection for a smooth surface, the apparent temperature, the sky 
temperature and the atmosphere temperature are function of $\alpha$ only. Through the inversion of the Fresnel's equation, an estimate of the effective dielectric constant of the emitting layer is obtained as:

$$
€_{\text {eff }}=\sin ^{2} \alpha+\cos ^{2} \alpha\left[\frac{\sqrt{R+1}}{\sqrt{R-1}}\right]^{2}
$$

Several models have been developed using the above concept. The model developed by Topp, Davis, Annan is the most widely used model.

Percentage soil moisture, (\%SM) according to Topp, Davis, Annan model is

$$
\begin{array}{r}
\% S M=0.00043(€)^{2}-0.055(€)^{2} \\
+2.92(€)-5.5
\end{array}
$$

Further another model for the ERDC data has been proposed in [17] which is also a third order polynomial in relative dielectric permittivity Percentage soil moisture (\%SM) according to ERDC model is

$$
\begin{gathered}
\% S M=0.000237(€)^{3}-0.03421(€)^{2}+2.435(€) \\
-2.86
\end{gathered}
$$

A careful study of these models reveal that the Topp, Davis and Annan model is more suitable for computing the volumetric moisture values in soil from dielectric permittivity measurements at a frequency above $100 \mathrm{MHz}$ and this model is frequency dependent. However, the ERDC model is suitable for computing the soil moisture values at low frequencies and within a normal range of soil moisture. However the authors of these models have not suggested any corrections for incorporating the effects of vegetation and surface roughness on the computed values of soil moisture. It has been widely accepted that, these effects are very predominant and it is vital to incorporate these effects in to the model in order to obtain the realistic values of soil moisture. In this paper the soil moisture values are computed using Topp, Davis and Annan model and the ERDC model for the two sets of data collected from the field covered with vegetation and for uneven (roughness) surface regions. These values are compared with the measured values of soil moisture (gravimetric method) and found that the errors in both these models are in the ranges of about 50 to $75 \%$

\section{PROPOSED MODEL}

The main objective of the proposed model is to appropriately incorporate the effects of surface roughness and vegetation cover of a particular region of study in to the existing models. In order to accomplish this, field data (uncorrected emissivities, roughness factors, NDVI at $6.6 \mathrm{GHz}$ and $18 \mathrm{GHz}$ frequencies) are obtained for a particular region along with the measured values of soil moisture. The emissivity data are appropriately corrected using the correction factors proposed in the literature to account for the effects of vegetation and surface roughness.

\subsection{Correction for the vegetation effect}

Jackson and Schmugge [18] have proposed an accurate model which accounts for vegetation effect on soil moisture based on the relationship between optical depth and the vegetation water content (VWC). For each vegetation type, a vegetation parameter was assigned based on published data. Vegetation water content was determined using NDVI values calculated using Land sat Thematic Mapper (LTM) images of the region. The following expressions are used to calculate the correction factor for the effects of vegetation:

$$
\begin{aligned}
& V W C=1.9134(N D V I)^{2}-0.3215(\mathrm{NDVI}) \\
& \quad \text { for NDVI }<0.5
\end{aligned}
$$

$$
\begin{aligned}
& V W C=4.2857(N D V I)^{2}-1.5439(\mathrm{NDVI}) \\
& \text { for NDVI }>0.5
\end{aligned}
$$

$$
\text { Optical depth }(J)=S(V W C)
$$

Where $\mathrm{S}$ is an empirically derived value for the slope of the regression line between VWC and $\mathrm{J}$ is Transmissivity of the observing layer

$$
\wp^{2}=\exp (2 J \sec \alpha)
$$

Where $\alpha=$ incidence angle (in this study it is 49.9 degrees) Now the corrected emissivity

$$
\mathrm{e}=1-R \wp^{2}
$$

Where $\mathrm{R}=$ uncorrected reflectivity which is obtained from the uncorrected emissivity (which is a data). These corrected emissivities are used to develop the proposed model.

\subsection{Corrections for the effect of roughness}

Since the observed microwave emission depends on the amount of scattering that takes place at the soil surface, necessary correction is required for rough surfaces. Choudhary et.al. [19] have proposed a simple model for correcting the effects of surface roughness, in which the smooth surface reflectivity is given by:

$$
R_{s}(\alpha)=R r(\alpha) \exp \left(h \cos ^{2} \alpha\right)
$$

Where $\mathrm{Rr}$ is the rough surface reflectivity at look angle $\alpha$ and $\mathrm{h}$ is given by:

$$
h=4 \sigma^{2}\left[\frac{2 \pi}{\lambda}\right]^{2}
$$

Where $\sigma^{2}$ is the variance of the height distribution of the surface and $\lambda$ is the observed wave length. These corrected reflectivities are used to obtain the emissivities and in turn they are used in the proposed model.

\subsection{Stepwise Procedure}

STEP:1 Collection of field data (Frequency, Emmisivity,Roughness Factor,NDVI,soil moisture)

STEP: 2 for a given NDVI the corrected values of emistivities (using equation (10)) are computed.

STEP: 3 the necessary correction to the emissivities computed above for different roughness (using equations (11) are obtained.

STEP: 4 the corrected reflectivities using corrected emistivities as obtained in step 3 are computed.

STEP: 5 Complex Dielectric constant ' $€$ 'using equation- 2.3 are calculated.

STEP: 6 Least square fit method is used to obtain the suitable order polynomial of $€$ (In this case it is $3^{\text {rd }}$ order polynomial). This process is continued till the model gives the 
soil-moisture value as close as possible to the measured value (with an acceptable least error).

The data collected from the field for seven different NDVIs, (0to 0.6) Three roughness factors (smooth, $\mathrm{h}=\mathrm{o}$, medium, $\mathrm{h}=0.2$ and rough, $\mathrm{h}=0.4$ ) and for two different frequencies $(6.6 \mathrm{MHz}, 18 \mathrm{GHz})$ are used in this study.

The resulting model is given by:

$$
(\% \mathrm{SM})=
$$

$$
\% \text { Volumetric moisture, }
$$

$0.00021(€)^{3}-0.069(€)^{2}+$

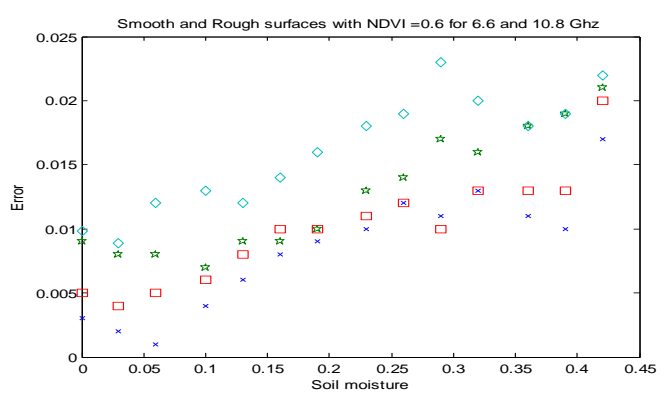

Figure 3 Proposed Model for NDVI= 0.6

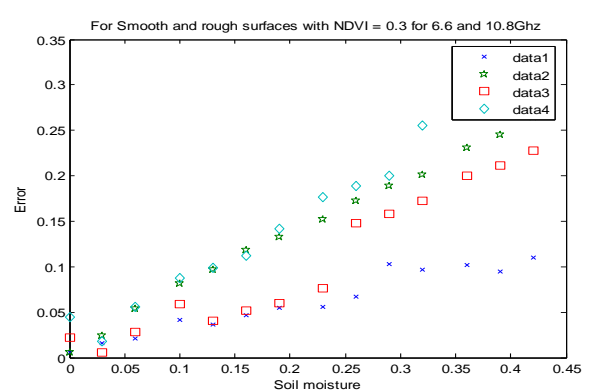

Figure 4 Graph of Annan model for NDVI = 0 effects. How ever the results of the proposed model yield very less error. The simulations are carried out using MATLAB simulation tool.

Data 1 for smooth surface with frequency of $6.6 \mathrm{GHz}$ Data 2 for rough surface with frequency of $6.6 \mathrm{GHz}$ Data 3 for smooth surface with frequency of $10.8 \mathrm{GHz}$ Data 4 for rough surface with frequency of $10.8 \mathrm{GHz}$

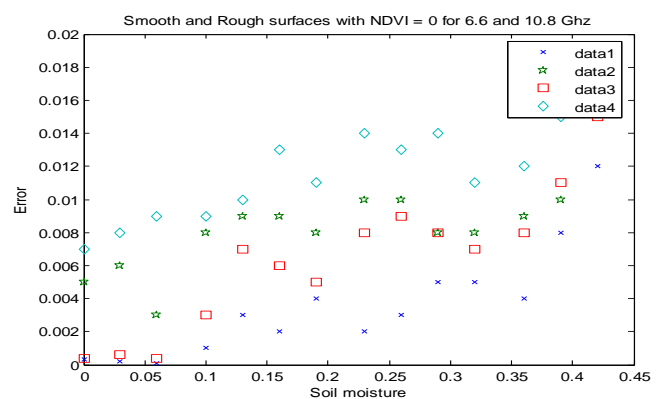

Figure 1 Proposed Model for NDVI= 0

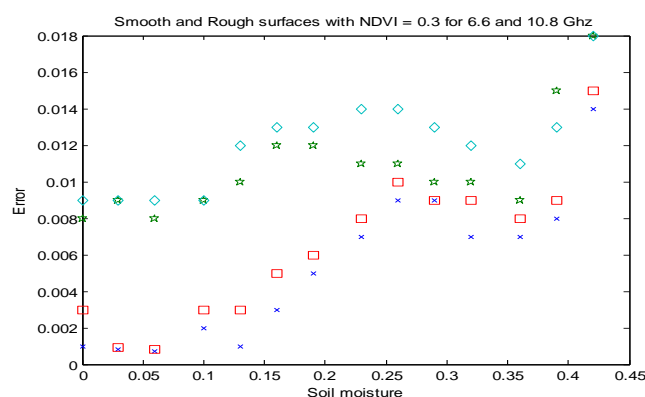

Figure 2 Proposed Model for NDVI=0.3

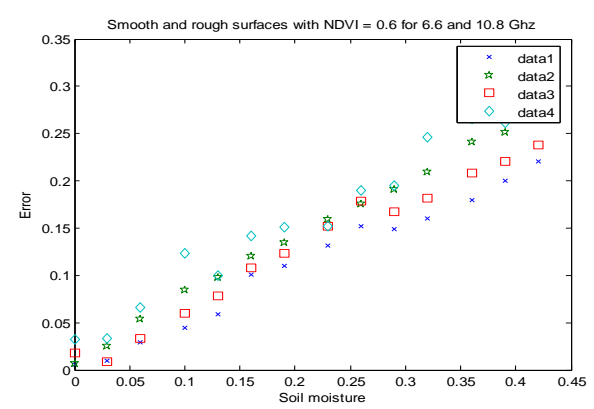

Figure 5 Graph of Annan model for NDVI $=0.3$

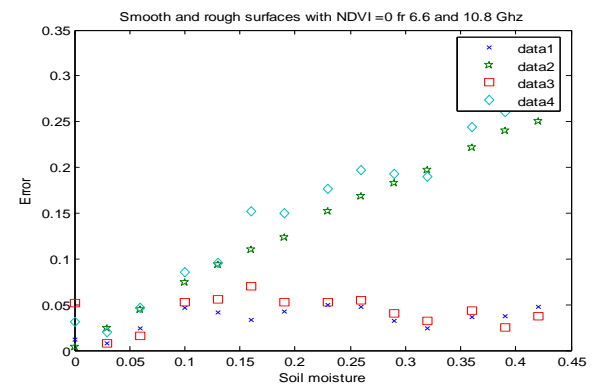

Figure 6 Graph of Annan model for NDVI = 0.6 


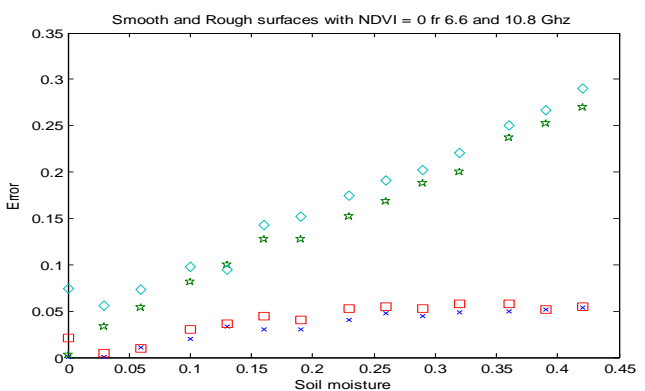

Figure 7 Graph of ERDC model for NDVI = 0

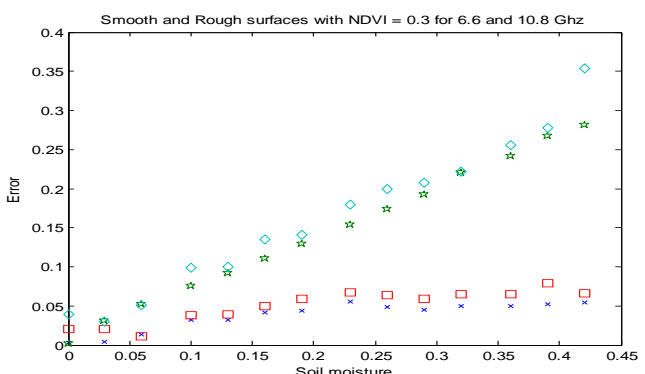

Figure 8 Graph of ERDC model for NDVI = 0.3

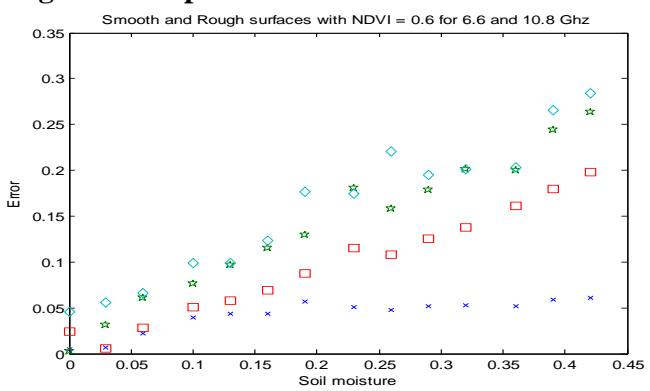

Figure 9 Graph of ERDC model for NDVI = 0.6

Following important observations are made from the results of this study.

1. The error in the computed values of soil moisture in previous models (TOPP, Davis and Annan model and the ERDC model) increases steeply for soil moisture values more than $40 \%$ however in the proposed model the increase in the error is considerably less.

2. Previous models yield an error of $10 \% \& 15 \%$ for rough surface at NDVI $=0.6$ (fig 6 and 9) however it is worth noting that the proposed model yields an error of $7.5 \%$ for the same case which is considerably less. (fig 3 ).

3. The proposed model is found to be more accurate for $6.6 \mathrm{GHz}$ than $18 \mathrm{GHz}$.

\section{ANN ARCHITECTURE}

Artificial Neural Networks are composed of simple elements operating in parallel. These elements are inspired by the functioning of biological nervous system. The key element of ANN paradigm is the novel structure of the interconnected processing elements that are analogous to neurons and are tied together with weighted connections that are analogous to synapses. The ANN is made to perform a particular function by adjusting the weights of the connections between them.
This process is known as training [20]. ANNs are used for diverse tasks including pattern recognition, function approximation, estimation, classification and prediction, hence emerging in the present technological scenario as a powerful computational tool as well as an integral part of the advances made in the field of artificial intelligence [21]. The learning of an ANN is a process by which the free parameters of a neural network are adapted through a process of simulations by the environment in which the network is embedded. There are many different mechanisms of learning, roughly classified into two groups as supervised and unsupervised learning. Many efficient algorithms have been designed and tested upon a wide variety of problems successfully. Significant efforts have been put in by the researchers in the point for the processing of remotely sensed data [22]. There are many algorithms which are used in developing and training the neural network. The back propagation algorithm is used in this paper to capture the nonlinear relationship between the input parameters and the respective model co-efficients.

\subsection{Design of ANN architecture:}

Selection of appropriate input-output variables is an important task in development of ANN architecture. Following input parameters are identified as key parameters in this study.
a) Frequency (f)
b) Emissivity (e)
c) Vegetation index (NDVI)
d) Roughness factor (h)
e) Look angle $(\alpha)$
f) Soil type (clay-00, Loam-01, Sandy loam -10, Sandy clay-11)

For these input parameters an appropriate model co-efficients are computed using proposed method explained in section 3 . Accordingly there are five output parameters for each set of inputs they are
a) Coefficient of $€^{3}$
b) Coefficient of $€^{2}$
c) Coefficient of $€$
d) Constant.
e) Soil moisture

Using the data collected from the field, 10 sets of input-output parameters are computed which is illustrated in table 1. Out of 10 sets 6 sets (which are highlighted in the table) are used as the training sets and architecture is designed. Based on trial and error simulations the ANN architecture as shown in table 2 is obtained. The ANN took 41 seconds of CPU time for training and an error goal of 1e-5 was achieved in 818 epochs. The convergence characteristics of ANN is shown in fig 13 
Table 1 Input Output Set

\begin{tabular}{|c|c|c|c|c|c|c|c|c|c|c|c|}
\hline \multicolumn{7}{|c|}{ ANN inputs } & \multicolumn{5}{|c|}{ ANN outputs } \\
\hline SN & $\begin{array}{l}\text { Freq } \\
\text { GHz }\end{array}$ & Emissivity & NDVI & $\mathrm{h}$ & $\begin{array}{l}\text { Look } \\
\text { Angle } \\
(\alpha)\end{array}$ & Soil type & $\begin{array}{l}\text { Coeff of } \\
€^{3}\end{array}$ & $\begin{array}{l}\text { Coeff } \\
\text { of } €^{2}\end{array}$ & $\begin{array}{c}\text { Coeff } \\
\text { of } €\end{array}$ & Const & $\begin{array}{l}\text { Soil } \\
\text { Moist } \\
.\end{array}$ \\
\hline 1 & 6.6 & 0.86 & 0 & 0 & 49.9 & Loam & 0.00020 & 0.059 & 3.802 & 3.01 & 0.059 \\
\hline 2 & 6.6 & 0.873 & 0.1 & 0.2 & 49.9 & Clay & 0.00021 & 0.061 & 3.709 & 2.92 & $\begin{array}{l}0.021 \\
2\end{array}$ \\
\hline 3 & 6.6 & 0.885 & 0.2 & 0.4 & 49.9 & $\begin{array}{l}\text { Sandy } \\
\text { clay }\end{array}$ & 0.00019 & 0.056 & 3.812 & 3.32 & $\begin{array}{l}0.031 \\
2\end{array}$ \\
\hline 4 & 10.8 & 0.943 & 0.4 & 0 & 49.9 & $\begin{array}{l}\text { Sandy } \\
\text { loam }\end{array}$ & 0.00022 & 0.061 & 3.912 & 3.42 & 0.425 \\
\hline 5 & 10.8 & 0.933 & 0.3 & 0.2 & 49.9 & Loam & 0.00030 & 0.060 & 3.898 & 3.92 & 0.159 \\
\hline 6 & & 0.939 & 0.5 & 0.4 & 49.9 & Clay & 0.00022 & 0.063 & 3.912 & 2.99 & 0.388 \\
\hline 7 & 18 & 0.994 & 0.6 & 0 & 49.9 & $\begin{array}{l}\text { Sandy } \\
\text { loam }\end{array}$ & 0.00018 & $\begin{array}{l}0.058 \\
2 \\
\end{array}$ & 3.789 & 3.42 & 0.256 \\
\hline 8 & 18 & 0.84 & 0 & 0.2 & 49.9 & $\begin{array}{l}\text { Sandy } \\
\text { clay }\end{array}$ & 0.00028 & 0.061 & 3.702 & 2.98 & 0.121 \\
\hline 9 & 18 & 0.869 & 0.2 & 0.2 & 49.9 & Clay & 0.00018 & 0.053 & 3.567 & 2.32 & 0.189 \\
\hline 10 & 18 & 0.881 & 0.3 & 0.4 & 49.9 & $\begin{array}{l}\text { Sandy } \\
\text { loam }\end{array}$ & 0.00023 & 0.056 & 3.643 & 3.45 & 0.352 \\
\hline
\end{tabular}

Table 2 ANN Architecture

\begin{tabular}{|lll|}
\hline No of Input neurons & $:$ & 6 \\
No of neurons in the first hidden layer & $:$ & 25 \\
No of neurons in the second hidden layer & $:$ & 16 \\
No of neurons in the output layer & $:$ & 4 \\
Training function & $:$ & Train $1 \mathrm{~m}$ \\
Learning rate & $:$ & 0.3 \\
Error goal & $:$ & $1 \mathrm{e}-5$ \\
Total number of epochs specified & $:$ & 1000 \\
Number of epochs taken to reach error goal & $:$ & 818 \\
\hline
\end{tabular}

Figure 13 Convergence characteristics of ANN

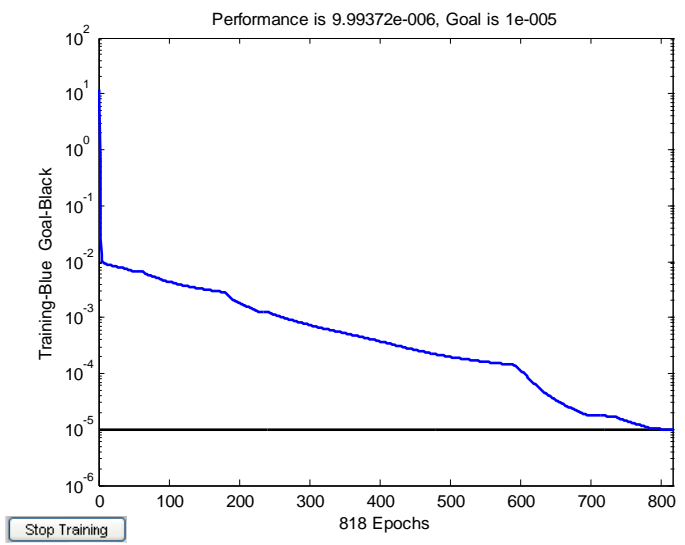

\subsection{Results:}

The performance of the designed ANN architecture in predicting the model coefficients was tested using the remaining input output data sets (not highlighted in table 2).The graph showing the difference between the computed and predicted values of the model coefficients is depicted in the Figure $14 \mathrm{a}-14 \mathrm{~d}$ It is evident from the graph that the ANN has accurately predicted the model coefficients for an unseen input pattern. Further these coefficients are used to compute the soil moisture and this is compared with the soil moisture obtained from the field measurement (in-situ measurement). The results are shown in table 3 and also depicted in the graphs 15 
Table 3 Computed and predicted values of co efficient

\begin{tabular}{|c|c|c|c|c|c|c|c|c|c|c|c|}
\hline No. & $\begin{array}{l}\text { Compute } \\
d \text { value } \\
\text { of Coeff } \\
\text { of } €^{3}\end{array}$ & $\begin{array}{l}\text { Predi } \\
\text { cted } \\
\text { value } \\
\text { of } \\
\text { Coeff } \\
\text { of } €^{3}\end{array}$ & $\begin{array}{l}\text { Comput } \\
\text { ed value } \\
\text { of Coeff } \\
\text { of } €^{2}\end{array}$ & $\begin{array}{l}\text { Predicte } \\
d \text { value } \\
\text { of Coeff } \\
\text { of } €^{2}\end{array}$ & $\begin{array}{l}\text { Compu } \\
\text { ted } \\
\text { value } \\
\text { of } \\
\text { Coeff } \\
\text { of } €\end{array}$ & $\begin{array}{l}\text { Predi } \\
\text { cted } \\
\text { Value } \\
\text { of } \\
\text { Coeff } \\
\text { of } €\end{array}$ & $\begin{array}{l}\text { Comp } \\
\text { uted } \\
\text { Value } \\
\text { of } \\
\text { Const } \\
\text {. }\end{array}$ & $\begin{array}{l}\text { Pred. } \\
\text { Value } \\
\text { of } \\
\text { Const } \\
\text {. }\end{array}$ & $\begin{array}{l}\text { Comp. } \\
\text { Value } \\
\text { of Soil } \\
\text { Moist. }\end{array}$ & $\begin{array}{l}\text { Pred. } \\
\text { Value } \\
\text { of Soil } \\
\text { Moist. }\end{array}$ & $\begin{array}{l}\text { Measu } \\
\text { red } \\
\text { value } \\
\text { of Soil } \\
\text { Moist. }\end{array}$ \\
\hline 1 & 0.000198 & $\begin{array}{l}0.000 \\
20\end{array}$ & 0.0593 & 0.059 & 3.821 & 3.802 & 3.051 & 3.01 & 0.061 & 0.059 & 0.06 \\
\hline 2 & 0.000201 & $\begin{array}{l}0.000 \\
21\end{array}$ & 0.0619 & 0.061 & 3.712 & 3.709 & 2.891 & 2.923 & 0.229 & 0.0212 & 0.23 \\
\hline 3 & 0.000191 & $\begin{array}{l}0.000 \\
19\end{array}$ & 0.0565 & 0.056 & 3.855 & .842 & 3.351 & 3.32 & 0.032 & 0.0312 & 0.03 \\
\hline 4 & 0.000212 & $\begin{array}{l}0.000 \\
22 \\
\end{array}$ & 0.0613 & 0.061 & 3.916 & .912 & 3.39 & 3.421 & 0.425 & 0.425 & 0.42 \\
\hline 5 & 0.000305 & $\begin{array}{l}0.000 \\
30 \\
\end{array}$ & 0.0611 & 0.061 & 3.899 & .898 & 3.89 & 3.92 & 0.155 & 0.159 & 0.16 \\
\hline 6 & 0.00023 & $\begin{array}{l}0.000 \\
22 \\
\end{array}$ & 0.0625 & 0.063 & 3.905 & .912 & 2.99 & 2.99 & 0.394 & 0.388 & 0.39 \\
\hline 7 & 0.000185 & $\begin{array}{l}0.000 \\
18 \\
\end{array}$ & 0.0572 & 0.0582 & 3.768 & .789 & 3.405 & 3.42 & 0.258 & 0.256 & 0.26 \\
\hline 8 & 0.000286 & $\begin{array}{l}0.000 \\
28\end{array}$ & 0.0615 & 0.061 & 3.752 & .742 & 2.975 & 2.982 & 0.105 & 0.121 & 0.1 \\
\hline 9 & 0.000191 & $\begin{array}{l}0.000 \\
18 \\
\end{array}$ & 0.0521 & 0.053 & 3.598 & .587 & 2.316 & 2.321 & 0.189 & 0.189 & 0.19 \\
\hline 10 & 0.000235 & $\begin{array}{l}0.000 \\
23\end{array}$ & 0.0562 & 0.056 & 3.712 & .723 & 3.35 & 3.452 & 0.362 & 0.352 & 0.36 \\
\hline
\end{tabular}

It is evident from the results that the proposed model for the computation of soil moisture and the designed ANN architecture have yielded very accurate results for the different sets of field data obtained at different frequencies.

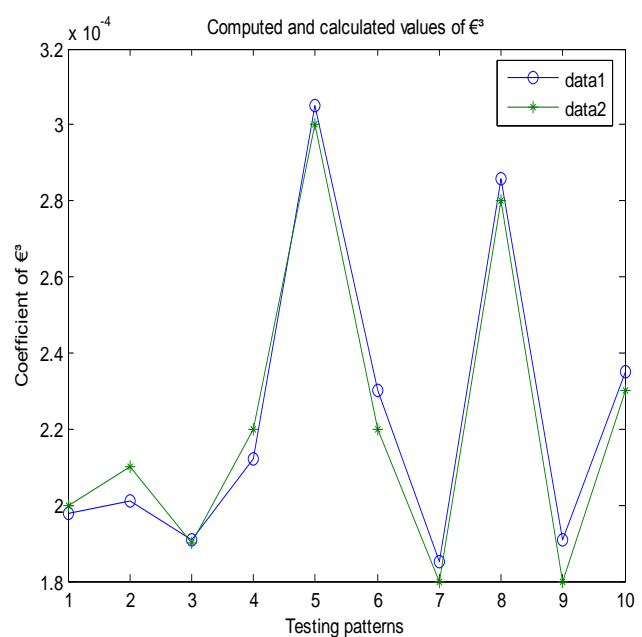

Graph 14a

Data 1 Computed Value of $€^{3}$ Data 2 Predicted value of $€^{3}$

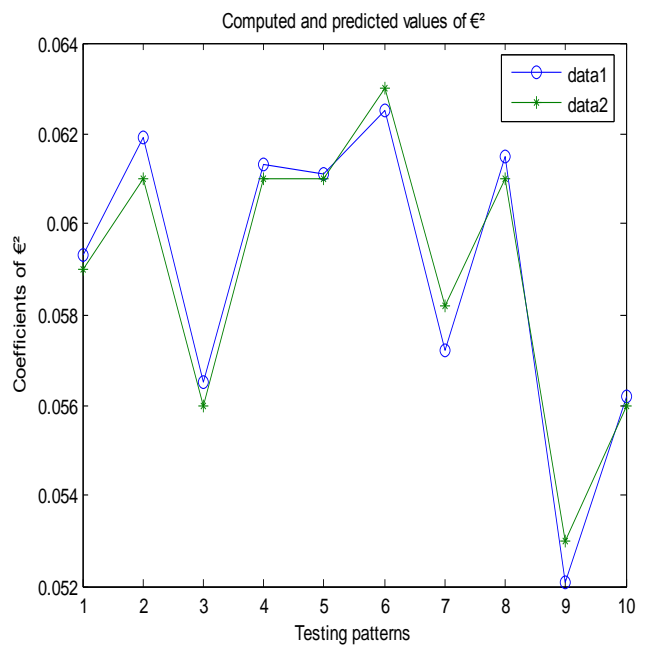

Graph 14b

Data 1 : Computed value of $\epsilon^{2}$

Data 2 : Predicted value of $€^{2}$ 


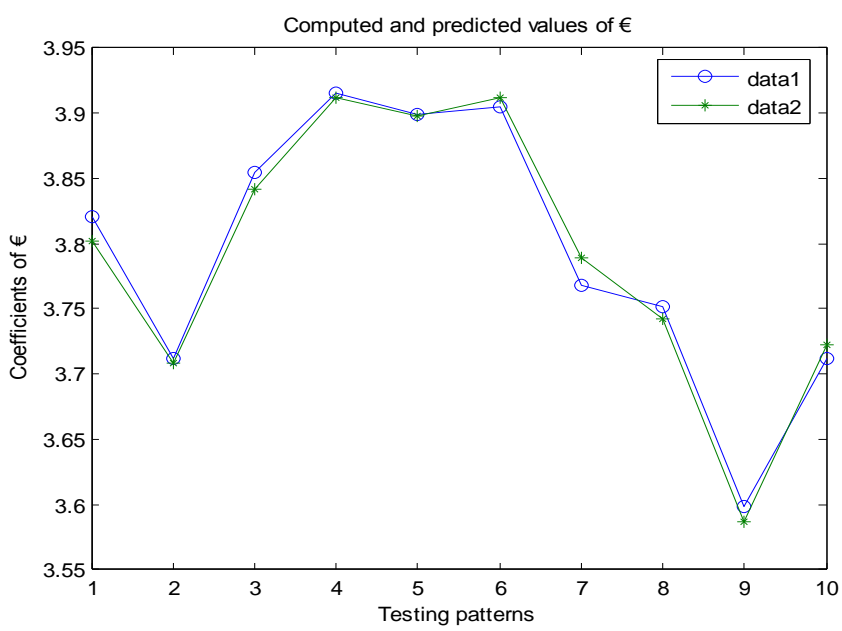

Graph 14c

Data 1 : Computed value of $€$

Data 2 : Predicted value of $€$

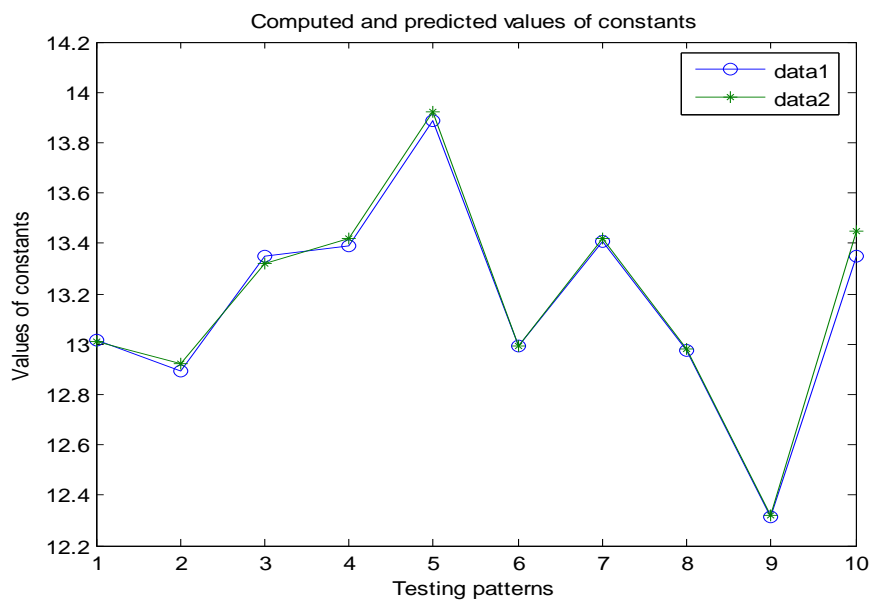

Graph 14d

Data 1: Computed value of Constant

Data 2: Predicted value of Constant

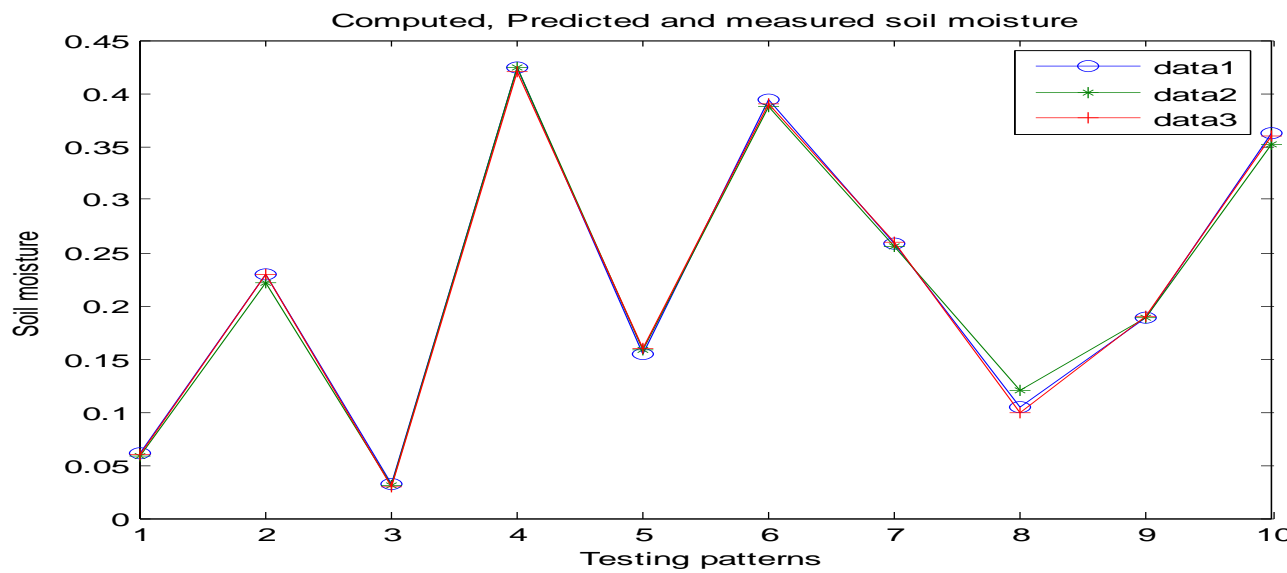

Graph -15

Data 1 : Computed value of soil moisture

Data 2 : Predicted value of soil moisture

Data 3 :IN - Situ measured value of soil moisture. 


\section{CONCLUSION}

A novel empirical model of third order polynomial has been developed using the remotely sensed data for computing the soil moisture incorporating the effects of vegetation and roughness. Further ANN architecture has been designed to predict the model parameters (model coefficients). Proposed empirical model and designed ANN architecture have been tested with the real time data and the results are found to be very accurate and hence can be used for accurate prediction of soil moisture.

\section{REFERENCES}

[1]. Wagner, W. Blooschal, G. Pamparon;, P. Calret, J.C. Bizzavvi operational roughness of microwave remote sensing of soil moisture for hydrologic NORD, HYDROL, 18 (1, 1-20, 2007)

[2]. Wang, J.R. and Schmugge, J.J "An empirical model for the complex dielectric permittivity of soil as a function of water content" IEEE Transactions.Geoscience,Remotesensing,Ge-18,288-295

[3]. Doblon, M.C Ulaby F.T.Hallikanien M.T And El Sayes M.A "Microwave Di electric behavioyr of wet soil-part II dielectric mixing models, IEEE Transactions, Geoscience,Remotesensing,Ge-23,35-46

[4]. Ulaby, F.T.Moore,R.K. and fing A.K. microwave remote sensing, active and passive, vol III from theory to applications,ArtechHome,Massachvset5tes.

[5]. NJOKU, E.G and Kong J.A "Theory for passive microwave remote sensing of mear-surface soil moisture Journal of Geo physics, Res, 82, 3108-3118.

[6]. John O Curtis "Moisture effects on the dielectric properties of soils. IEEE, transactions on Geosciences and remote sensing. Vol 39, No 1, pp - 125-128 jan 2007.

[7]. M.Baker and R.R. Allmaras, system for automating and multiplexing soil moisture measurement by time domain reflectometry". "Soil sci,soc,Amer.J.vol 54pp,16 jan-feb, 1990

[8]. R.Caldecott, M.poirer,and D.E. Svoboda " A radio frequency probe to measure soil electrical properties." "The ohio state univ. Columbus,Final Rep 715,616-4 jan 1985

[9]. Campbell Dielectric probe manual V.103 Horseshoe bend, IN Campbell Consulting Dec 1998.
[10].J.E.Hipp "Soil electromagnetic parameters as functions of frequency, soil density,and soil moisture Proc IEEE Vol 62,PP 98-103,Jan 1974

[11].G.R. Olheofrt and D.E. Carpon "Laboratory Measurements of the radiofrequency electrical and magnetic properties o soil from near yuma Arizona "U.S.Geolog Surey,Denvar, CO Open file Rep 93-701

[12].A.M.Thomas "In situ measurement of moisture in soil and similar substances by n"fringe" capacitance,"J.Sci Instrum Vol 43,pp 21-27 1966

[13].Hornik K., Multilayer feed forward network are universal approximators, Neural Networks, vol 2 no5, pp 359 366, 1989.

[14].Dawson M.S. et al "Surface parameter retrieval using fast learning neural networks", Remote sensing reviews, vol 7 pp 1-18, 1993.

[15].V.Atluri, H.Chih-cheng and T.L.Coleman "An artificial neural network for classifying and predicting soil moisture and temperature using Levenberg-Marquardt algorithm" presented at Southeastcon 99 proceedings IEEE 1999

[16].Schmugge J "Microwave of surface soil moisture and temperature in remote sensing of biosphere functioning (R.j. Hobbs and H.A. Money,eds) springer-Verlag, Newyork.

[17].A.M.Thomas "In situ measurement of moisture in soil and similar substances by "n fringe" capacitance, "J Sci Instrum vol 43 pp $21-271966$

[18].T.J.Jackson and T.J Schmugge, "vegetation effects on the microwave emission of soils", Remote sensing of environment, vol 36 p $203-212,1991$

[19].Choudhary B.J, Schmugge T.J Newton, R.W and chang A.T.C. "Effects of surface roughness on microwave emission of soils", journal of geophysics Res., 84, pp $5699-5706$

[20].Bishop, C.M., "Neuralnetworks and their applications" Review of scientific instruments, vol 65, $1803-1832$ june 1994

[21]. Widrow B and N.A Lehr, "Thirty years of adaptive neural networks: perceptron, madaline and backropagation", Proceedings of IEEE vol 78, no9, 1415 - 1442, September 1990.

[22].Loyala D.G "Application of neural network methods to the processing of earth observation satellite data", Neural networks, vol 19, $168-177,2006$. 